\title{
LAS COMPENSACIONES ECONÓMICAS LUEGO DE EXTINGUIDO EL VÍNCULO MATRIMONIAL O LA UNIÓN CONVIVENCIAL EN EL NUEVO CÓDIGO CIVIL Y COMERCIAL ARGENTINO
}

\author{
Mariel F. Molina de Juan* \\ "Cuando el Código entra en un hogar, es que antes el amor le ha hecho sitio, \\ saliéndose de él" \\ Carlos María Entrena Klett
}

Recibido: 16.08 .2014

Aprobado: $16.09,2014$

\section{RESUMEN}

El artículo reflexiona sobre las compensaciones económicas, una nueva institución que incorpora el Código Civil y Comercial argentino $^{1}$ como un efecto patrimonial objetivo del divorcio incausado y del cese de las uniones convivenciales.

Esta figura tiene por finalidad corregir el injusto desequilibrio que el divorcio o la ruptura de la unión producen, como consecuencia de los roles y responsabilidades asumidos por los cónyuges o convivientes durante la vida en común, que llevaron a que uno de ellos posponga o relegue su desarrollo personal o profesional, en miras al proyecto compartido. Aunque ambos realizaron esfuerzos y cooperaron para llevar adelante la familia y alcanzar una calidad de vida acorde a sus expectativas, al momento del quiebre, el que debió dejar el trabajo o sus estudios y no pudo concluir su carrera profesional u obtener una mejor posición laboral, sufre un perjuicio directo frente al otro. Ese desequilibrio, que se mantenía oculto, ahora se hace visible.

Las compensaciones económicas se presentan entonces, como una herramienta orientada al reequilibrio y la autonomía económica de cada uno de los miembros de la pareja con posterioridad a la extinción del vínculo matrimonial o convivencial.

\section{PALABRAS CLAVE}

Compensaciones económicas -Desequilibrio patrimonial - Divorcio - Ruptura de la Unión Convivencial -Autonomía económica -Código Civil y Comercial argentino.

\section{ABSTRACT}

The article reflects on the financial offsets, a new institution included in the Civil and Commercial Code of Argentina ${ }^{1}$, as the objective impact on property resulting from divorce and the cessation of common-law marriage.

The purpose of such financial offsets is to correct the unfair imbalance resulting from divorce or breakup of marriage due to the roles and responsibilities assumed by the spouses or partners during their life together, which led to one of them postponing or relegating his/her personal or professional development, for the sake of a common project. Although both cooperated and made efforts to care for their family and to achieve a quality of life commensurate with their expectations, at the time of the breakup, whoever stopped working or dropped out of school and was unable to complete his/her career or get a better job position, suffers direct harm vis a vis the other party. This imbalance, which remained hidden, now becomes visible.

Financial offsets surface as a tool to rebalance and provide economic independence to each of the spouses or partners after the ending of the civil marriage or common-law marriage.

\section{KEY WORDS}

Financial offsets - Imbalanced assets -Divorce - Ending of common-law marriage- economic independence -Civil and Commercial -Code of Argentina.

* Abogada, Doctora en Derecho Universidad Nacional de Cuyo (Argentina). Miembro del equipo docente del Doctorado en Derecho (UNC). Colaboradora en la Reforma de Código y Comercial para la redacción del libro de las Relaciones Familiares.

1 Sancionado el 1 de octubre de 2014. Promulgado el 7 de octubre de 2014. Ley 26.944. 


\section{SUMARIO}

1. Preliminares. 2. El contexto de la propuesta. 3. Antecedentes. 4. Fundamentos. 5. Requisitos de procedencia. 5.1. Desequilibrio económico manifiesto. 5.2. Empeoramiento de la situación del que la reclama. 5.3. Causa adecuada. 5.4. Sentencia firme de divorcio o cese de la unión. 6. Determinación. 7. Cumplimiento. 8. Extinción. 9. Naturaleza jurídica. 9.1. No son alimentos. 9.2. No son daños y perjuicios. 9.3. Una respuesta posible. Naturaleza propia. 10. Conclusiones.

\section{Preliminares}

En el artículo anterior de esta Revista, he tenido la oportunidad de comentar una de las novedades que incorpora el nuevo Código Civil y Comercial argentino: la regulación de las uniones convivenciales, vieja práctica social durante largo tiempo ignorada o incluso menospreciada por el ordenamiento jurídico nacional.

En esta oportunidad, mis reflexiones se orientan al estudio de otra novedad: las compensaciones económicas previstas para el caso de divorcio, nulidad de matrimonio o cese de la unión convivencial.

La nueva ley argentina contempla las compensaciones económicas en el Libro Segundo correspondiente a las Relaciones de familia ${ }^{2}$. La Sección Tercera, que se ocupa de los "Efectos del divorcio," comprende específicamente dos instituciones: (a) la atribución de la vivienda (artículo 443) y (b) la compensación económica (arts. 441 y $442)^{3}$. La figura resulta aplicable, además, a los supuestos de anulación del matrimonio, exclusivamente para el cónyuge de buena fe (conf. arts. 428 y 429) y, con algunas variantes, en el caso de cese de las uniones convivenciales (arts. 524 y 525). ${ }^{4}$

Pronto se verá que esta institución se asienta en situaciones de gran cotidianeidad. Con frecuencia, la ruptura de la vida en común genera una desigualdad económica anclada en la distribución de roles y responsabilidad desde los miembros de la pareja, con el consiguiente perjuicio del más vulnerable, generalmente - aunque no exclusivamente - la mujer.

2 Se han manifestado a favor de la incorporación de esta figura, entre otros, AMOREO, María Cristina. "La pensión compensatoria en el reparto de ganancialidad”. En: Revista de Derecho de Familia y de las Personas, La Ley. Buenos Aires: septiembre 2012, p. 50.

3 El artículo 441 expresa: "El cónyuge a quien el divorcio produce un desequilibrio manifiesto que signifique un empeoramiento de su situación y que tiene por causa adecuada el vínculo matrimonial y su ruptura, tiene derecho a una compensación. Esta puede consistir en una prestación única, en una renta por tiempo determinado o, excepcionalmente por plazo indeterminado. Puede pagarse con dinero, con el usufructo de determinados bienes o de cualquier otro modo que acuerden las partes o decida el juez". El artículo 442 establece las pautas para su fijación y la caducidad del derecho. El texto dice: "A falta de acuerdo de los cónyuges en el convenio regulador, el juez debe determinar la procedencia y el monto de la compensación económica sobre la base de diversas circunstancias, entre otras: a) el estado patrimonial de cada uno de los cónyuges al inicio y a la finalización de la vida matrimonial; b) la dedicación que cada cónyuge brindó a la familia y a la crianza y educación de los hijos durante la convivencia y la que debe prestar con posterioridad al divorcio; c) la edad y el estado de salud de los cónyuges y de los hijos; d) la capacitación laboral y la posibilidad de acceder a un empleo del cónyuge que solicita la compensación económica; e) la colaboración prestada a las actividades mercantiles, industriales o profesionales del otro cónyuge; f) la atribución de la vivienda familiar, y si recae sobre un bien ganancial, un bien propio, o un inmueble arrendado. En este último caso, quién abona el canon locativo. La acción para reclamar la compensación económica caduca a los SEIS (6) meses de haberse dictado la sentencia de divorcio".

$4 \quad$ El artículo 524 expresa: "Cesada la convivencia, el conviviente que sufre un desequilibrio manifiesto que signifique un empeoramiento de su situación económica con causa adecuada en la convivencia y su ruptura, tiene derecho a una compensación. Ésta puede consistir en una prestación única o en una renta por un tiempo determinado que no puede ser mayor a la duración de la unión convivencial. Puede pagarse con dinero, con el usufructo de determinados bienes o de cualquier otro modo que acuerden las partes o en su defecto decida el juez".

El artículo 525 contempla las pautas para la fijación judicial de la compensación económica y la caducidad. El texto dice: "El juez determina la procedencia y el monto de la compensación económica sobre la base de diversas circunstancias, entre otras: a) el estado patrimonial de cada uno de los convivientes al inicio y a la finalización de la unión; b) la dedicación que cada conviviente brindó a la familia y a la crianza y educación de los hijos y la que debe prestar con posterioridad al cese; c) la edad y el estado de salud de los convivientes y de los hijos; d) la capacitación laboral y la posibilidad de acceder a un empleo del conviviente que solicita la compensación económica; e) la colaboración prestada a las actividades mercantiles, industriales o profesionales del otro conviviente; f) la atribución de la vivienda familiar. La acción para reclamar la compensación económica caduca a los SEIS (6) meses de haberse producido cualquiera de las causas de finalización de la convivencia enumeradas en artículo 523". 
En mi opinión, ambas figuras compensaciones económicas y uniones convivenciales- comparten una gran pertinencia social en tanto pretenden brindar respuestas a hechos notorios y a problemáticas sociales actuales y comprobables. El derecho opera, una vez más, como mecanismo de control social para evitar abusos e injusticias.

En adelante trataré de ofrecer algunas claves para visualizar el contenido esencial de la nueva figura incorporada.

\section{El CONTEXTO DE LA PROPUESTA}

La institución engarza dentro del sistema de divorcio introducido por el Código Civil y Comercial argentino, ${ }^{5}$ en el que se prescinde de invocar y acreditar toda "causa" para obtener una sentencia judicial que disuelva el vínculo matrimonial ${ }^{6}$.

\section{El régimen es incausado ${ }^{7}$.}

Por un lado, porque suprime el examen de culpa de uno u ambos cónyuges en la ruptura matrimonial ${ }^{8}$; recoge, así, los serios cuestionamientos de la doctrina y la jurisprudencia al sistema subjetivo del Código Civil vigente9. Los motivos que impulsaron a los esposos para solicitar su divorcio quedan reservados a la esfera de la intimidad de la pareja sin que sea necesario el control ni la injerencia del Estado en una cuestión tan personalísima que, por lo demás, no compete al interés público.

Por el otro, porque la garantía de protección de los derechos fundamentales, especialmente la esfera de autonomía personal, exige la eliminación de todo requisito objetivo para la procedencia del divorcio, como el cumplimiento de un plazo del matrimonio o de separación de hecho para peticionarlo.

De este modo, el Código Civil y Comercial argentino recientemente sancionado, procura "desdramatizar" el divorcio y estimular soluciones responsables, propiciando y privilegiando la realización de convenios para resolver los efectos de esa ruptura.

El divorcio puede ser demandado judicialmente por acuerdo de ambos (bilateral) o bien por voluntad de uno solo de los esposos (unilateral); en otras palabras, el matrimonio no se sostiene si no es por la decisión de los dos cónyuges; si uno de ellos tiene voluntad de no continuarlo, el otro no puede resistirse ni oponerse al dictado de la sentencia que ponga fin al vínculo matrimonial.

El divorcio incausado, la consagración del principio de autosuficiencia y la recepción del postulado de igualdad en términos de "igualdad real de oportunidades", fundamenta la sustancial modificación que el Código Civil y Comercial imprime a los alimentos posteriores al divorcio, a los cuales asigna un carácter claramente excepcional (conf. art. 434).

Este diseño sigue las tendencias legislativas más progresistas en la materia, ${ }^{10}$ así por ejemplo,

5 Se aparta de la propuesta del Proyecto del año 1998, que fue tomado como fuente para la redacción de muchas instituciones, pues ese proyecto, además de mantener la doble vía de separación personal y divorcio, se adscribió al régimen de divorcio causado.

6 Las relaciones entre los cónyuges son vistas más como cuestiones privadas que públicas, propiciando una mayor autonomía en la regulación del contenido del matrimonio y su disolución. Por eso, en numerosos sistemas legislativos, el acceso al divorcio se ha venido flexibilizando progresivamente, con una tendencia hacia un divorcio basado en causales objetivas 0 aunque se mantenga el divorcio sanción, se le retacean efectos de modo de desalentar el proceso contencioso (ARIANNA, Carlos. "Reflexiones sobre las prestaciones post divorcio. Apuntes para una reforma". En: RDF 52 -2011, p. 34.).

7 A favor del divorcio incausado, SOLARI, Néstor. "Criterios de fijación de la prestación compensatoria". En: Revista de derecho de familia y las personas. La Ley. Buenos Aires: Junio 2014, p. 27/29.

8 Con ello se pretende morigerar el desgaste emocional que generan los procesos con atribución de culpas, no solo a los cónyuges involucrados en juicios contenciosos, sino también a todas sus familias. Por otra parte, se reconoce la dificultad real para establecer un solo culpable de la ruptura matrimonial, toda vez que habitualmente las crisis matrimoniales se deben a una multiplicidad de causas y concausas que se superponen. Más aún, teniendo en cuenta que la determinación de las causas de los conflictos matrimoniales queda sujeta a las reglas probatorias procesales y que muchas veces los jueces no alcanzan a conocer la realidad de los hechos que transcurrieron en la intimidad de las parejas.

9 Entre otros, “D., M. C. c. B., M. A. s/divorcio y dis. de sociedad conyugal”, ED, 233-132, BORDA, Guillermo J., "Crisis del divorcio-sanción”, LL 2012-B, 1262; MIZRAHI, Mauricio Luis, "Los alimentos entre cónyuges divorciados por causales objetivas. Desdoblamiento interpretativo del artículo 209 del Código Civil”, LL 2009-B- 1104.

10 La reforma al Código Civil francés del año 2004 consagró la extinción del deber alimentario entre cónyuges divorciados. En el Código Civil español solo existen los alimentos que pueden acordarse en el convenio regulador de los efectos del divorcio (artículo 90). La ley de matrimonio civil de Chile también excluye la obligación alimentaria luego del divorcio (conf. artículo 60). 
la de la Comisión de Derecho Europeo de Familia ${ }^{11}$ cuya recomendación sobre "Principios de derecho Europeo de Familia relativos al divorcio y a los alimentos entre esposos divorciados", establece como regla general que cada esposo ha de satisfacer sus propias necesidades tras el divorcio.

En este contexto, el Código argentino apunta a que, luego de la ruptura del matrimonio, cada uno de los cónyuges desarrolle las estrategias necesarias para su propio sostenimiento en el nuevo proyecto de vida que emprenda, sin depender "económicamente" del otro ${ }^{12}$. De este modo, pretende evitar las enojosas situaciones que genera la dependencia económica, que en definitiva repercute en una estigmatización de uno de los ex cónyuges y dificulta las relaciones familiares posteriores al divorcio.

Naturalmente, ello no quiere decir que se avale el abuso del derecho ni el enriquecimiento sin causa, que puede configurarse cuando exista una desigualdad patrimonial causada por la asunción de roles y responsabilidades de los cónyuges o convivientes durante la vida en común (por ejemplo si originariamente ambos se encontraban insertos en el mercado laboral, pero luego acordaron que uno de ellos renuncie al empleo para dedicarse al cuidado de los hijos y las tareas del hogar o para colaborar en la actividad desarrollada por el otro, sea profesional, comercial, empresaria, etc.). En consecuencia, aunque ambos compartieron esfuerzos y trabajaron a la par para llevar adelante la familia y alcanzar una calidad de vida acorde a sus expectativas, al momento de la ruptura, el que debió dejar el trabajo o sus estudios y no pudo concluir su carrera profesional u obtener una mejor posición laboral, sufre un perjuicio directo frente al otro.

Por eso se incorporan las compensaciones económicas, una herramienta jurídica que pre- tende evitar que se consoliden esas desigualdades injustas entre los miembros de la pareja que se disuelve. ${ }^{13}$

\section{AnteCEDENTES}

Las compensaciones económicas son derecho vigente en algunos sistemas legislativos que comparten su tradición jurídica con el derecho argentino, aunque con diferentes nombres: prestaciones compensatorias, pensiones compensatorias, prestaciones post divorcio, etc.

Es una figura bastante nueva, que surgió en Europa hacia el último cuarto del siglo $X X$, y fue incorporada por las legislaciones de Francia, España, Italia, Dinamarca, Alemania. En América, por El Salvador, Quebec y, más recientemente, Chile ${ }^{14}$. Es interesante destacar que aunque en todas ellas subyace un sustrato común, cada uno de estos países le asigna funciones específicas y acomoda sus presupuestos y caracteres a su propia realidad. ${ }^{15}$

11 Esta Comisión fue creada el 1 de septiembre de 2001 con el principal objetivo de impulsar un ejercicio de reflexión teórica y práctica relativo a la armonización del Derecho de familia en Europa. (https: / /e-justice.europa.eu) El principio 2.1 unifica las reglas alimentarias "cualquiera que sea la forma de divorcio".

12 Arianna se pronunció por la extinción del deber de alimentos entre cónyuges luego del divorcio, y la incorporación de la prestación compensatoria, que resulta más congruente con el estado de divorciado y que además permite otras alternativas valiosas, como su mayor flexibilidad en cuanto a la forma de pago, la limitación temporal y su carácter disponible (ARIANNA, Carlos. "Reflexiones sobre las prestaciones post divorcio". En: RDF 2011, 52, p 45).

13 En los Fundamentos elaborados por la Comisión de Reformas se precisa: "El Anteproyecto recepta una figura que tiene aceptación en varias legislaciones del derecho comparado, y que es coherente con el régimen incausado de divorcio; en efecto, con fundamento en el principio de solidaridad familiar y en que el matrimonio no sea causa fuente de enriquecimiento o empobrecimiento económico de un cónyuge a costa del otro, se prevé la posibilidad de que, para aminorar un desequilibrio manifiesto los cónyuges acuerden o el juez establezca compensaciones económicas. Estas compensaciones pueden ser abonadas de diferentes modos: prestación dineraria única; renta por un tiempo determinado o, de manera excepcional, por plazo indeterminado. Por ejemplo, si al momento de contraer nupcias se optó por llevar adelante una familia en la cual uno solo de los cónyuges era el proveedor económico y el otro cumplía sus funciones en el seno del hogar y en apoyo a la profesión del otro, no sería justo que al quiebre de esa elección se deje desamparado a aquél de los cónyuges que invirtió su tiempo en tareas que no se traducen en réditos económicos; en este caso, se le fijará una compensación económica que puede asumir distintas modalidades de pago: pensión, cuotas, etc. Nada impide que los cónyuges convengan su monto y forma de pago, pero, como se trata de un caso de protección legal con fundamento en la solidaridad familiar, ante la falta de acuerdo el juez puede determinar su procedencia y fijar su monto si correspondiere".

14 Ampliar en FANZONATO, Eduardo Ignacio. "Prestaciones compensatorias y alimentos entre ex cónyuges". En: Revista de Derecho Privado y Comunitario 2001 - I Alimentos; Buenos Aires: Rubinzal Culzoni, 2001, p. 20.

15 Compulsar VELOSO VALENZUELA, Paulina; “Algunas reflexiones sobre la compensación económica, en GROSMA -HERRERA (Dir) (2007). Hacia la armonización del derecho de familia en el MERCOSUR y países asociados. Buenos Aires: Lexis Nexis, p. 167. 
Por eso, no es fácil elaborar una definición única ni identificar los requisitos de manera uniforme y válida para las diferentes latitudes que la regulan, como así tampoco precisar su naturaleza. La experiencia comparada muestra que a veces trae elementos asistenciales, otras veces, elementos resarcitorios, o incluso notas o caracteres propios, que oscurecen toda posibilidad de delimitarla en forma nítida. ${ }^{16}$

En Francia, por ejemplo, Jean Carbonnier la ha definido como "aquella que tiene por finalidad asegurar la restauración del equilibrio entre dos situaciones patrimoniales cuya disparidad era ocultada precisamente por la comunidad de vida." ${ }^{17}$ En España, como "aquella prestación satisfecha normalmente en forma de renta periódica, que la ley atribuye, al margen de toda culpabilidad, al cónyuge que con posterioridad a la sentencia de separación o divorcio se en- cuentre - debido a determinadas circunstancias, ya sean personales o configuradoras de la vida matrimonial - en una situación económica desfavorable en relación con la mantenida por el otro esposo y con la disfrutada durante el matrimonio y dirigida fundamentalmente a restablecer el equilibrio entre las condiciones materiales de los esposos, roto con la cesación de la vida conyugal." ${ }^{18}$ Encarna Roca Trías, sostiene que su aplicación "propicia la superación de la pérdida económica que el divorcio puede provocar en alguno de los cónyuges, especialmente cuando el matrimonio haya producido una desigualdad entre las capacidades de ambos de obtener ingresos; cuestión que en la mayoría de las oportunidades, el régimen económico matrimonial resulta incapaz de solucionar."19 Otro autor español la define como"la cantidad periódica que un cónyuge debe satisfacer a otro tras la separación o el divorcio, para compen- sar el desequilibrio padecido por un cónyuge (el acreedor), en relación con el otro cónyuge (el deudor), como consecuencia directa de dicha separación o divorcio, que implique un empeoramiento en relación con su anterior situación en el matrimonio". ${ }^{20}$

Las primeras experiencias en el derecho comparado las regularon sólo en relación al derecho matrimonial. El progresivo reconocimiento jurídico de las uniones convivenciales, llevó a que también sea utilizada para subsanar los menoscabos económicos padecidos por la unión desavenida.

En Argentina, aunque el Código Civil derogado no las contempló, pueden rastrearse algunos antecedentes exclusivamente en relación con el divorcio. Han sido tratadas por la doctrina ${ }^{21}$ que destaca sus beneficios, ${ }^{22} \mathrm{e}$ invocadas por alguna jurisprudencia precursora ${ }^{23}$.

16 Conf. ARIANNA, Carlos, Reflexiones sobre las prestaciones post divorcio. Apuntes para una reforma. Cit.

17 CARBONNIER, Jean, "La question du divorce", Memoire a consulter, p. 120.

18 CAMPUZANO TOMÉ (1986): La pensión por desequilibrio económico en los casos de separación y divorcio. Especial consideración de sus presupuestos de otorgamiento. Barcelona: Librería Bosch, p. 28.

19 ROCA, Encarna (1999). Familia y cambio social (De la "casa” a la persona). Madrid: Cuadernos Civitas.

20 ZARRALUQUI SANCHEZ-EZNARRIAGA, Luis (2005). La pensión compensatoria en la nueva ley del divorcio: su temporalización y su sustitución. Sevilla.

21 FANZOLATO realizó una investigación sobre el tema; distinguió entre las prestaciones compensatorias civiles y las previsionales (Ampliar en FANZOLATO, Eduardo, Ignacio. "Prestaciones compensatorias y alimentos entre ex cónyuges". En: Revista de Derecho Privado y Comunitario, 2001 - I Alimentos; Buenos Aires: Rubinzal Culzoni, p. 19 y ss). Ver también los trabajos de GROSMAN, Cecilia "Tendencias actuales en el derecho alimentario de los cónyuges divorciados". En: LL 1982-A - 750; AZPIRI, Jorge O. “Aproximación a la pensión compensatoria”. En: RDF 19- 2001, p. 65; BELLUSCIO, Augusto, “Alimentos y prestaciones compensatorias”, En: LL 1995-A -1032.

22 AZPIRI, Jorge O., “Aproximación a la pensión compensatoria", Op. cit.

23 En una sentencia dictada en el año 2009 por la Suprema Corte de Buenos Aires, la disidencia del Dr. De Lázzari introdujo la consideración de esta figura como "paliativo" frente a las injustas consecuencias que el divorcio objetivo produciría en la mujer, quien padecía una enfermedad neurológica muscular de piernas y brazos de larga data, y necesitaba de acompañante terapéutico en cada una de las escasas actividades que realizaba. El voto ponderó que "a las dificultades para participar en el mercado de trabajo ante la incapacidad padecida se le sumará la pérdida de obra social y una probable imposibilidad de cobertura médica asistencial por el alto costo exigido si pretende adscribirse a la misma obra social al ser una persona mayor, enferma y sin actividad remunerativa (...) Reconoció que la mujer no tendrá derecho a los alimentos amplios (art. 207 CC) que le permiten mantener el "nivel de vida", aunque en el plano fáctico probablemente contribuyera con dinero ganancial para que éste fuera titular del beneficio jubilatorio que hoy sustenta en forma personal, pues no se ha juzgado la culpabilidad." Por eso, con argumento en el principio de igualdad y equilibrio entre hombre y mujer -con rango constitucional- sostuvo la aplicabilidad al caso de las compensaciones económicas "consistentes en contemplar una pensión por desequilibrio como una prestación pecuniaria a favor del cónyuge que realizó sacrificios patrimoniales directos o indirectos a causa de la relación matrimonial. (SCBA, 25 de noviembre de 2009; C. 98.408, "L. , A. B. contra C., E.L. . Divorcio contradictorio. Beneficio",www.scba.gov.ar/jurisprudencia BA B32240). 


\section{Fundamentos}

La figura se encuentra anclada en el paradigma del derecho constitucional familiar argentino, que propende al reconocimiento y la eficacia de los derechos fundamentales, el respeto por la autonomía personal, la plena manifestación del modelo igualitario, y el principio de responsabilidad familiar.

La autonomía personal se manifiesta en un doble sentido: por un lado, propicia que cada uno pueda reelaborar su proyecto de vida en forma independiente, y; por otro, faculta a los interesados a acordar la procedencia y el contenido del derecho. ${ }^{24}$

La igualdad va mucho más allá de la mera "igualdad formal" y se propone alcanzar la igualdad real de oportunidades. Como punto de partida, reconoce que la vida en pareja puede haber generado injustas desigualdades económicas, es decir, admite una posible desigualdad de facto, pero no se queda en ella, ofrece una herramienta concreta para que aquel que se ha visto desfavorecido por la tarea asumida durante la vida en común, pueda corregir esa diferencia, y obtener recursos económicos para su desarrollo autónomo.

Por último, responde al principio de responsabilidad que limita el ejercicio de la libertad exigiendo un obrar responsable con aquellos con quienes se ha compartido "vida familiar". Reconoce los sacrificios, postergaciones y renuncias vinculados con el desarrollo personal y profesional de cada uno, los que no deben ser ignorados si producen un resultado injusto. De este modo, aún a falta de acuerdo, el perjudicado podrá solicitar su fijación por la vía judicial para "compensar" el menoscabo y atenuar su impacto hacia el futuro.

\section{REQUISITOS DE PROCEDENCIA}

La circunstancia que haya finalizado unilateralmente o de común acuerdo el proyecto de vida en común no da lugar, de por sí, a la compensación económica. En otras palabras, el derecho a obtenerla no opera como consecuencia inmediata o necesaria del divorcio o cese de la unión; solo procede si se dan los siguientes requisitos previstos por la ley:

\subsection{Desequilibrio económico manifiesto:}

El concepto de desequilibrio económico es un concepto complejo, que implica una dualidad comparativa. Desequilibrio en relación con el otro miembro de la pareja, y desequilibrio en relación la propia situación personal (empeoramiento de la situación anterior).

Para que proceda la compensación, el divorcio o la ruptura de la unión, tiene que generar una desigualdad en las posibilidades económicas y de inserción laboral de una cierta entidad, que justifique poner en marcha este mecanismo compensatorio, es decir, no toda diferencia da lugar a la pretensión.

No se exige una situación de necesidad, por lo que puede percibirse incluso si se tienen medios económicos para subsistir. ${ }^{25}$

El desequilibrio debe existir en el momento de la ruptura, sin que las circunstancias sobrevenidas o las alteraciones posteriores den derecho a la prestación, y tiene que configurarse en relación a la última etapa de la convivencia, siempre que las circunstancias económicas fueran relativamente estables y con una proyección futura razonablemente segura, y no producto de acontecimientos pasajeros.

\subsection{Empeoramiento de la si- tuación del que la reclama:}

Debe configurarse un perjuicio concreto de la situación del que la peticiona que signifique un descenso en el nivel de vida y en sus posibilidades concretas, aunque no es función de la compensación garantizar el mantenimiento del estándar de vida anterior.

El perjuicio se revela en el presente y proyecta sus consecuencias negativas al futuro, empeo-

24 En el derecho chileno, Lepin Molina analiza la autonomía para pactar su procedencia y monto en el convenio regulador. Sostiene que las facultades del juez para subsanar las deficiencias de los acuerdos sobre compensaciones, están restringidas y se reducen a aprobar o rechazar el acuerdo, pero no pueden alterar su contenido. ("La autonomía de la voluntad y protección del cónyuge más débil en la determinación y formas de pago de la compensación económica", Revista lus et Praxis año 18 No. 1 Universidad de Talca 2012, p 3-36 y LEPIN MOLINA (Dir) (2013). Compensación económica. Doctrinas esenciales, Santiago de Chile: Thomson Reuters, p.445).

25 Para el divorcio, ver Trib. Sup. España Sala I en lo Civil, 03.10.2011; Diario La Ley N 7746, Sección La Sentencia del día, 29 de nov. 2011 Año XXXII ed. La Ley. La ley 18620/2011. 
rando la situación económica del beneficiario.

\subsection{Causa adecuada:}

Depende directamente de la distribución de roles y responsabilidades cumplidos por ambos durante el matrimonio o la unión, que provoca menoscabo a uno de ellos cuando ya no viven juntos.

Exige que la organización familiar sea causa adecuada del desequilibrio económico posterior, pero las razones por las que optaron por una u otra dinámica funcional no interesan.

En otras palabras, el miembro desfavorecido se debe encontrar con que, en razón de haber aportado sus esfuerzos al proyecto compartido o al desarrollo del otro, su propio crecimiento personal ha quedado postergado, y por ello, ahora está en peores condiciones de obtener ingresos para afrontar la vida en forma independiente.

\subsection{Sentencia firme de divor- cio o cese de la unión:}

Solo es exigible luego de la sentencia firme de divorcio o luego del cese de la unión convivencial, aunque puede haber sido pactada en el convenio regulador de los efectos del divorcio realizado durante las tratativas para alcanzar los acuerdos previos.

\section{Determinación}

Una de las cuestiones más difíciles de resolver, gira en torno a la determinación del quantum de la compensación. El artículo 442 ofrece una serie de pautas enunciativas.

La premisa es que no pretende restituir lo perdido por su equivalente exacto, ni igualar patrimonios o lograr un equilibrio exacto entre ambos ${ }^{26}$.

Al tratarse de una herramienta correctiva del desequilibrio en las posibilidades económicas, debe realizarse un análisis comparativo de la situación patrimonial al inicio y al momento del cese, esto es como obtener una "fotografía" del estado patrimonial de cada uno, y, si se constata ese desequilibrio, proceder a su justa recomposición." ${ }^{27}$ Deberá cotejarse la situación de ambos miembros, comparar la del más desfavorecido con la que tenía durante la convivencia, valorar las circunstancias presentes y las futuras previsibles, y realizar un análisis cuantitativo y cualitativo de todas ellas.

Por eso, la norma ofrece una serie de parámetros objetivos:

(i) las condiciones existentes al comienzo de la unión;

(ii) el análisis de cómo se han distribuido los roles y responsabilidades durante la vida familiar: La dedicación que cada uno brindó a la crianza y educación de los hijos y la colaboración prestada en actividades mercantiles, industriales y profesionales del otro. En este caso deberá ponderarse la prestación de trabajo efectivo dirigi- da al desarrollo o mayor rendimiento de esa actividad, sea o no la principal, valoración que exigirá un cuidadoso análisis para no confundir entre aquello que importa colaboración efectiva y el deber de asistencia y ayuda mutua que existe entre los miembros de la pareja. En todos estos casos, habrá de ponderarse la existencia o no de un enriquecimiento injusto.

(iii) las circunstancias existentes al momento de la ruptura y su evolución en un futuro previsible: Aquí se comprenden las condiciones personales de los miembros del grupo familiar, edad y estado de salud (para apreciar las posibilidades de desenvolvimiento autónomo), si alguno de ellos está próximo a la jubilación, si tiene una enfermedad crónica o accidental (por ej. los gastos que genera la enfermedad, la cobertura social, la relación entre la enfermedad y la actividad laboral, etc.). También deberá valorar la cualificación y situación profesional en relación con el mercado laboral del cónyuge que la solicita, calibrada con la actividad y posibilidades del que debe pagarla; la capacitación laboral, las posibilidades de adquirirla o completarla, las circunstancias especiales para ejercerla. Asimismo se debe tomar en cuenta la dedicación futura al cuidado de los hijos, y se incorpora un parámetro novedoso (que no aparece expresado en los antecedentes del derecho comparado): la atribución de la vivienda familiar.

Aunque las pautas brindadas por la norma no son taxativas,

\footnotetext{
26 En el mismo sentido, para el derecho matrimonial chileno, ver PIZARRO WILSON, Carlos, VIDAL OLIVARES, Álvaro (2009). La compensación económica por divorcio o nulidad matrimonial. Santiago de Chile: Legal Publishing, p. 35.

27 Fundamentos del Anteproyecto elaborados por la Comisión redactora.
} 
al ser una figura objetiva, debe alertarse sobre el riesgo de caer en la tentación de introducir como elementos valorativos la culpabilidad o inocencia en la ruptura o el divorcio, ${ }^{28}$ que no deben tomarse en cuenta para la decisión.

\section{Cumplimiento}

La regla general es la autonomía personal para elegir la forma de cumplirlas.

A modo de ejemplo, el Código señala que puede consistir en una prestación única o en una renta por tiempo determinado y pagarse con dinero, con el usufructo de determinados bienes o de cualquier otro modo.

En principio, la idea que encierra la norma, es que la compensación se fije una sola vez y que su carácter sea inmutable, aunque su pago se haya previsto en cuotas. La prestación única tiene como ventajas la comodidad y rapidez, permite disponer al momento del divorcio de un capital con el cual reequilibrar la situación, y evita los conflictos que pueden generarse mediante el pago de renta, porque "soluciona el problema de una vez por todas." Sin embargo, presenta el inconveniente de requerir una capacidad económica del deudor que no siempre existe.

La compensación estipulada en forma indeterminada en el tiempo, sólo es posible en el caso de divorcio y con carácter absolutamente excepcional. ${ }^{29}$

\section{EXTINCIÓN}

El derecho a la compensación económica se extingue automáticamente por: (i) renuncia, (ii) cumplimiento de la condición resolutoria acordada o fijada judicialmente, (iii) transcurso del plazo señalado, o (iv) cumplimiento íntegro de la prestación debida.

Otro modo de extinción, previsto específicamente es la caducidad. Las compensaciones integran esa clase de facultades que nacen con una vida limitada en el tiempo, porque el derecho a obtenerlas cesa si se omite ejercerlo dentro del plazo fijado por la ley. ${ }^{30}$

En cambio, no se encuentra subordinada a que su beneficiario contraiga nupcias o viva en unión convivencial, pues tales situaciones resultan ajenas al fundamento esencialmente compensador de la figura.

\section{Naturaleza JuRídica}

He dejado para el final el análisis de su naturaleza jurídica, porque la respuesta exige un mayor estudio de la regulación elaborada y sus fundamentos. No obstante, es importante reflexionar sobre ella, para poder definir qué régimen resulta aplicable a todo aquello que no ha sido previsto expresamente, especialmente, porque el marco normativo dado a las compensaciones económicas por el Código Civil y Comercial argentino es limitado. Solo contempla los presupuestos de procedencia, las pautas para su determinación, la forma de cumplimiento, su contenido, y caducidad. Pero muy probablemente la aplicación en la práctica requiera precisar otros efectos, como por ejemplo, si son disponibles, renunciables, compensables, embargables, transmisibles, si son susceptibles de prescripción, si pueden modificarse, etc. ${ }^{31}$

En una primera aproximación, puede afirmarse que se trata de un derecho de naturaleza patrimonial, que se traduce en una prestación económica con notas propias. Aunque presenta puntos de contacto con otras figuras como los alimentos, el

28 SOLARI, Néstor. Criterios de fijación de la prestación compensatoria. Op. cit.

29 La limitación temporal prevista como regla para el caso de ex cónyuges, recoge la posición de Carlos Arianna que argumenta del siguiente modo: la temporalidad de la prestación conjuga tres elementos: a) coloca el cónyuge que resultó más perjudicado en una situación de potencial igualdad de oportunidad a la que habría tenido de no mediar matrimonio; b) evita que el divorcio sea una fuente de renta parasitaria c) permite al acreedor rehacer su vida. (Ampliar "Reflexiones sobre las prestaciones post divorcio", cit.).

30 Se ha sostenido que el plazo de caducidad debería extenderse a un año, pues el considerable acortamiento del proceso de divorcio que trae el Proyecto no permitirá al cónyuge que tiene derecho a reclamarlas, el acomodamiento, los cambios de hábitos y el necesario duelo (conf. AMOREO, María Cristina; La pensión compensatoria en el reparto de ganancialidad; cit.; Ver también dictamen de mayoría en las XXIV Jornadas Nacionales de Derecho Civil y SAMBRIZZI, Eduardo, "Las compensaciones económicas entre los cónyuges en el Proyecto de Código Civil", Revista de Derecho de Familia y de las Personas. Buenos Aires: La Ley; N 11, Diciembre, 2013, p. 36.

31 En la experiencia chilena, la primera inquietud de la doctrina nacional fue dilucidar la naturaleza jurídica de la compensación económica, aunque en la actualidad el debate parece haberse trasladado sobre aspectos de índole más práctico. (Conf. PIZARRO WILSON, Carlos, VIDAL OLIVARES, Álvaro; La compensación económica por divorcio o nulidad matrimonial. Op. cit., p. 11) 
resarcimiento por los daños, la equidad o el enriquecimiento sin causa, no se confunde con ninguna de ellos ${ }^{32}$. Veamos algunas diferencias.

\subsection{No son alimentos}

*Se ha procurado diferenciarlas de la obligación alimentaria desde la misma denominación; nótese que prescinde de la voz "pensión" (que tiene más que ver con la renta asistencial que podría asociarse a un elemento de periodicidad), y en cambio utiliza la fórmula "compensación económica" que realza su naturaleza patrimonial.

*La compensación no pretende atender a la subsistencia del beneficiario, sino corregir el menoscabo económico que padece.

*Pueden fijarse aún en caso que no exista necesidad, requisito ineludible para los alimentos ${ }^{33}$.

*Los alimentos se encuentran regidos por la regla "rebus sic stantibus," la compensación se fija teniendo en cuenta el desequilibrio al momento de la ruptura.
*Los alimentos son inherentes a la persona (no se pueden ceder, compensar, transar, embargar, transferir por actos entre vivos y son irrenunciables); las compensaciones se presentan como un derecho de crédito, consecuentemente se aplican las normas de las obligaciones de dar.

*Las compensaciones no proceden cuando se han fijado alimentos post divorciales. Esta incompatibilidad no tiene por finalidad asimilar ambas instituciones, sino remarcar el carácter excepcional de la prestación alimentaria posterior al divorcio y revalorizar el principio de autosuficiencia antes explicado. Es decir, si existe una situación de desigualdad que pueda ser compensada, hay que atender primero a ella, y para el caso que no se den los presupuestos de procedencia de las compensaciones, no hayan sido reclamadas, o hayan caducado, queda habilitada la vía de la prestación alimentaria.

\subsection{No son daños y perjuicios}

*Si bien su pago importa el reconocimiento de un menosca- bo, no puede confundirse con la indemnización por los daños y perjuicios que se funda en la culpa. ${ }^{34}$ Prescinde del elemento subjetivo y se concentra estrictamente en el desequilibrio económico objetivo. ${ }^{35}$

*Pero ello no implica asociarlas con la responsabilidad de naturaleza objetiva, ${ }^{36}$ ni importa una reparación del lucro cesante. ${ }^{37}$

*Tiene en cuenta la situación personal y patrimonial del obligado, y trata de corregir un desequilibrio patrimonial en lugar de reparar integralmente el daño injustamente causado.

*Si el interesado ha sido víctima de un daño en su persona, puede reclamar indemnización en el sentido estricto del término, siempre que se configuren los presupuestos de la responsabilidad civil.

\section{3. Una respuesta posible. Naturaleza propia}

Partiendo de la dificultad para encuadrarla en un molde preestablecido, ¿en qué consistiría la esencia de esta figura?

32 Para un análisis comparativo entre estas instituciones pero limitado al divorcio, ver también MOLINA DE JUAN, Mariel F., “Las compensaciones económicas en el divorcio". En: RDF No. 57-2012, p. 187 y No. 59 p. 143 (Ponencia Premiada en el XVII Congreso Internacional de Derecho Familiar. Mar del Plata, 2012).

33 "Los alimentos y la pensión compensatoria obedecen a finalidades y causas distintas: así como los alimentos tienen como objetivo solucionar el estado de necesidad de quien los acredita, la pensión compensatoria obedece a otras razones, cuales son las de compensar el desequilibrio que pueda producirse como consecuencia de la ruptura matrimonial. De este modo, se ha reconocido que para reclamar la pensión compensatoria no se requiere la prueba de la necesidad" (Sup Trib España Sala 1 9.02.2010 http://www.lexfamily.es/revista.php?codigo=795.

34 En el mismo sentido, el Supremo Tribunal Español (10.03.09) 1130/2009, ID Cendoj 28079110012009100152 (www.poderjudicial.es).

35 Compulsar Arianna, Carlos, Reflexiones sobre las prestaciones post divorcio, op. cit.

36 Aunque se ha postulado una asimilación a la responsabilidad objetiva como "responsabilidad legal o sin culpa"; sus especificidades propias la alejan de la responsabilidad civil (LEPIN MOLINA, Cristina, 2010, La compensación económica. Efecto patrimonial de la terminación del matrimonio. Santiago de Chile: Ed. Jurídica de Chile, p. 93).

37 Con toda claridad, Pizarro y Vidal Olivares explican que aunque el lucro cesante puede ser un instrumento idóneo para el cálculo de su cuantía, las compensaciones no tienen por finalidad indemnizar la perdida por lo que se dejó de percibir por dedicarse a la familia y no haber podido desarrollar una actividad remunerada (La compensación económica por divorcio o nulidad matrimonial; cit. p. 37). 
*En principio, podría concluirse que es un efecto patrimonial de la ruptura que impone a uno de los miembros de la pareja ejecutar una prestación de dar en beneficio de otro. ${ }^{38}$

*Tiene fundamento legal; procede solo si se configuran los requisitos previstos expresamente, sin perjuicio de la facultad de las partes de acordarlas.

* Se deben en tanto existió un proyecto familiar común disuelto, que generó un desequilibrio económico perjudicial para uno de sus miembros, y que la responsabilidad familiar no puede ignorar.

*Es objetiva, prescinde de la culpa en la ruptura.
*Una vez fijada por sentencia judicial o por acuerdo homologado, nace un derecho personal para el beneficiario, ingresando a su patrimonio, con todas las implicancias legales que ello representa.

\section{Conclusiones}

Mientras duran el amor y la armonía, lo más común es que la dinámica de la vida en pareja responda a la cooperación para alcanzar los objetivos de cada uno, y los compartidos; pero cuando se produce la ruptura, muy probablemente la forma en que se han desempeñado durante todo ese tiempo condicione el futuro, que tendrá que ser afrontado por cada uno de ellos con los recursos que ha podido forjarse.
Si las posibilidades de ambos están desequilibradas en razón de esa historia familiar, el desajuste (que hasta entonces se mantenía "oculto" o "compensado") se hace visible.

Aquí es donde cobra relevancia la incorporación de esta nueva figura al Código Civil y Comercial argentino, que brinda la posibilidad de fijar una prestación económica en beneficio del perjudicado, poniendo a su alcance una herramienta jurídica que potencia la igualdad real de oportunidades, para que cada uno tenga la posibilidad de diseñar en forma autónoma su nuevo proyecto de vida, de elegir los medios para concretarlo y de poner en marcha las estrategias adecuadas para su realización.

38 Sigue la idea de Pizarro Wilson, Carlos y Vidal Olivares, Álvaro; La compensación económica por divorcio o nulidad matrimonial; cit. p.. 32 y 35. Para Lepin Molina, es el único efecto patrimonial que nace con la terminación del matrimonio (ampliar en La compensación económica. Efecto patrimonial de la terminación del matrimonio. cit. p. 55). Ver también Corral Talciani, quien sostiene que no es propiamente asistencial o alimenticia (porque el matrimonio se extingue y con ello el deber de socorro) ni tampoco una manifestación del enriquecimiento sin causa (si efectivamente lo hay podrá reclamarse por una acción autónoma), ni tampoco una forma de responsabilidad civil contractual objetivada por lucro cesante o pérdida de chance (lo que también podría ser objeto de una acción independiente). La figura cae más bien en las llamadas en España indemnizaciones por sacrificio; sería entonces una indemnización por afectación lícita de derechos, similar a las indemnizaciones legales que se pagan en caso de expropiación o de imposición de servidumbres legales (ampliar en "La compensación económica en el divorcio y la nulidad matrimonial”. En: Rev. Chilena de Derecho, Volumen 34 N 1 Santiago de Chile, Pontificia Universidad Católica de Chile, 2007, p 23-40; actualizado y aumentado en Separación, nulidad y divorcio. Análisis desde los principios y reglas de la ley de matrimonio civil, Santiago, Abeledo Perrot, 2011, p 91-120, y en Lepin Molina (Dir) (2013). Compensación económica. Doctrinas esenciales, Santiago de Chile: Thomson Reuters, p. 170). 